\title{
Sınıf ve Fen Bilgisi Öğretmen Adaylarının Yenilene- bilir Enerji Kaynaklarına Yönelik Tutumlarının Bazı Değişkenlere Göre İncelenmesi*
}

\author{
Nur Leman BALBAĞ, Mustafa Zafer BALBAĞ ${ }^{* *}$ \\ Sınıf ve Fen Bilgisi Öğretmen Adaylarının Yenile- \\ nebilir Enerji Kaynaklarına Yönelik Tutumlarının \\ Bazı Değişkenlere Göre İncelenmesi
}

\section{Özet}

$\mathrm{Bu}$ araştırmada Sınıf (SÖ) ve Fen Bilgisi (FBÖ) Öğretmen adaylarının, yenilenebilir enerji kaynaklarına yönelik tutumlarının bazı değişkenlere göre (cinsiyet, bölüm, akademik başarı, mezun olunan lise türü) karşılaştırıması amaçlanmıştır. Çalışmada, nicel araştırma yöntemlerinden tarama modeli kullanıımışır. Araştırmanın çalışma grubunu, 2016-2017 eğitimöğretim yllında bir devlet üniversitesinin Eğitim Fakültesinde öğrenim gören sınıf ve fen bilgisi öğretmen adayları oluşturmaktadır. Araştırmaya katılan toplam öğretmen adayı sayısı 180 olup, bunların $101^{\prime} i$ sınıf, 79 'u fen bilgisi öğretmen adayıdır. Araştırmada veri toplama aracı olarak Güneş vd. (2013) tarafından geliştirilen "Yenilenebilir Enerji Kaynaklarına Yönelik Tutum Ölçeği" kullanılmıştır. Araştırma sonuçları incelendiğinde öğretmen adaylarının söz konusu yenilenebilir enerji kaynaklarına ilişkin tutumlarının, genel olarak olumlu olduğu görülmektedir. Cinsiyet değişkenine göre, toplam puanda istatistiksel olarak anlamlı farkın kadın öğretmenlerin lehine olduğu görülmektedir. Anahtar Kelimeler: Tutum, Öğretmen Adayı, Yenilenebilir Enerji Kaynakları, Fen Eğitimi

\author{
Elementary and Science School Teacher Candi- \\ dates' Attitudes towards Renewable Energy \\ Sources According to Some Variables \\ Abstract
}

In this study, it is aimed to compare the pre-service teachers' attitudes towards renewable energy sources according to some variables (gender, department, academic achievement, graduated high school type). In this study, survey model of quantitative research methods was used. The study group of the consisted of elementary and science prospective teachers who are in the Faculty of Education of a state university in the academic year of 2016-2017. The total number of prospective teachers participating in the study was 180, of which 101 were elementary and 79 were science teacher candidates. In this research, "The Attitude Scale for Renewable Energy Resources" was used as the data collection tool developed by Güneş et al. (2013). When the results of the study are examined, it is observed that the attitudes of the prospective teachers towards renewable energy sources are generally positive. According to the gender variable, it is seen that there is a statistically significant difference in total score in favor of female teachers.

Key Words: Attitude, Prospective Teachers, Renewable Energy Sources, Science Education

\section{Giriş}

Çağımızda her alanda hızla gerçekleşen teknolojik gelişmeler enerji ve enerjiye olan gereksinimi de arttırmaktadır. Günümüzde ağılıklı olarak kullanılmakta olan kömür ve

\footnotetext{
*Bu çalışmanın bir kısmı, 14 - 16 Eylül 2017 tarihleri arasında Uşak Üniversitesinde düzenlenen I. Uluslararası Eğitim Araştırmaları ve Öğretmen Eğitimi Kongresinde sözlü bildiri olarak sunulmuştur.

${ }^{* *}$ Nur Leman BALBAĞ, Dr. Öğr.Üyesi, Uşak Üniversitesi, Eğitim Fakültesi, nurleman.goz@usak.edu.tr, ORCID ID orcid.org/0000-0002-5166-9076, Mustafa Zafer BALBAĞ, Doç. Dr., Eskişehir Osmangazi Üniversitesi, Eğitim Fakültesi, zbalbag@ogu.edu.tr, ORCID ID orcid.org/0000-0002-2328-0848
} 
petrol içerikli enerji kaynaklarının (Koroneos, vd. 2003) kısa zaman içerisinde tükenecek olması ve çevreye verdiği zararlar insanoğlunu yeni ve temiz enerji kaynaklarına arayışa yönlendirmiş, yenilenebilir enerji kaynaklarının önemini arttırmıştır. Bu anlamda yenilenebilir enerji kaynaklarının etkili kullanımı birçok açıdan son derece önemlidir. Kömür ve petrol gibi fosil yakıtların kullanılmasının sonucu olarak atmosfere $\mathrm{CH}_{4}, \mathrm{CO}_{2}, \mathrm{NO}, \mathrm{N}_{2} \mathrm{O}$ ve $\mathrm{NO}_{2}$ gibi gazlar salınmaktadır. Bu gazlara sera gazları denilmektedir. Bu gazların atmosferde bulunma oranlarının yükselmesi; küresel ısınmadan, iklim değişikliklerine kadar pek çok olumsuzluğu da beraberinde getirmektedir (Cebesoy, 2016). Dolayısıyla sera gazlarının bu olumsuz etkilerinden korunabilmek için yenilenebilir enerji kaynakların kullanımının artırılması gerekmektedir (Saatçioğlu \& Küçükaksoy, 2004). Yenilenebilir enerji kaynakları pek çok olup bunlar, güneş, rüzgâr, hidroelektrik, jeotermal, biokütle, hidrojen, dalga ve gelgit enerjisi olarak sıralanabilir. Ülkemizde kullanılan enerji kaynakları arasında yenilenebilir enerjinin kullanımı çok düşük seviyelerdedir. Kullanımının az olması nedeniyle toplumumuzdaki bireylerin de bu konu üzerindeki bilgisi oldukça yetersizdir. Toplumumuzun, yenilenebilir enerji kaynakları ve bu kaynakların sürdürülebilirliği konusunda bilgilendirilmesi gerekmektedir. Bu bilgilendirme ise eğitim ile gerçekleşebilir. Eğitim, davranış değişikliklerini meydana getirerek yenilenebilir enerji kaynaklarına yönelik toplumun sahip olması gereken bilinç, tutum ve gelişimi sağlayarak, sürdürülebilirliği konusundaki hassasiyeti aşılayabilir. Ancak, bu eğitimlerin doğru kanallardan ve doğru bir şekilde verilmesi önemlidir. Yenilenebilir enerji kaynaklarının kullanılmasının ve öneminin her açıdan değerlendirilerek topluma sunulması gerekmektedir. Bu sunumu yapabilecek birçok araç mevcuttur. Yazılı ve görsel medya, sivil toplum örgütleri, kitaplar, öğretmenler vb. bunlara örnek olarak verilebilir. Buradaki her araç, toplumun yenilenebilir enerji kaynakları ile onların çevre ve sağlıkla ilişkisi konularında etkin olarak kullanılabilir. Bunların içerisinde öğretmenlerin de oldukça büyük önemi vardır. Ağaç yaş iken eğileceğinden, özellikle, yenilenebilir enerji kaynakları ile ilgili bilgi sahibi olan öğretmenler bu konudaki bilinç ve tutumu kazandırmada öğrencilerine yol gösterebilir; bu kaynakları günlük yaşamlarında kullanabilecekleri uygun yeterlilikleri kazandırmada rehber olabilirler (Liarakou vd., 2009). Bireylerin öğrenme durumlarını olumlu ya da olumsuz yönde etkileyen en önemli duyuşsal özelliklerden birisi tutumdur (Bindak, 2004). Bu nedenle yenilenebilir enerji kaynaklarına yönelik olumlu ve pozitif tutumların oluşturulması önemlidir. Yenilenebilir enerji kaynaklarına yönelik olumlu tutumların geliştirilmesi bireylerin çevresi, ailesi ve aldığı eğitim ile ilgilidir (Güneş vd., 2013). Bu nedenle, geleceğin temel inşasını gerçekleştirecek olan öğretmen ve dolayısıyla öğretmen adaylarının yenilenebilir enerji kaynakları konusundaki bilgileri, tutumları ve davranışları büyük bir önem arz etmektedir.

Bu araştırmada Sınıf ve Fen Bilgisi Öğretmen adaylarının, yenilenebilir enerji kaynaklarına yönelik tutumlarının bazı değişkenlere göre (cinsiyet, öğrenim gördükleri bölüm, 
akademik başarı, mezun olunan lise türü) karşılaştırılması amaçlanmıştır. Bu temel amaç doğrultusunda aşağıdaki sorulara yanıt aranmıştır.

1. SÖ ve FBÖ öğretmen adaylarının yenilenebilir enerji kaynaklarına yönelik tutumları nasıl değişmektedir?

2. SÖ ve FBÖ öğretmen adaylarının yenilenebilir enerji kaynaklarına yönelik tutumları cinsiyete göre nasıl farklılaşmaktadır?

3. SÖ ve FBÖ öğretmen adaylarının yenilenebilir enerji kaynaklarına yönelik tutumları öğrenim gördükleri bölüme göre nasıl farklılaşmaktadır?

4. SÖ ve FBÖ öğretmen adaylarının yenilenebilir enerji kaynaklarına yönelik tutumları akademik ortalamaya göre nasıl farklılaşmaktadır?

5. SÖ ve FBÖ öğretmen adaylarının yenilenebilir enerji kaynaklarına yönelik tutumları mezun oldukları lise türüne göre nasıl farklılaşmaktadır?

\section{Yöntem}

Sınıf ve Fen Bilgisi Öğretmen adaylarının yenilenebilir enerji kaynaklarına yönelik tutumlarının bazı değişkenlere göre incelendiği bu araştırmada nicel araştırma yöntemlerinden tarama modeli kullanılmıştır. Tarama modelleri, var olan bir durumu ortaya çıkarmak için kullanılır(Karasar, 2009).

\section{1. Çalışma Grubu}

Araştırmanın çalışma grubunu 2016-2017 eğitim-öğretim yılında bir devlet üniversitesinin Eğitim Fakültesi SÖ ve FBÖ Programı'nda öğrenim gören lisans öğrencileri oluşturmaktadır. Araştırmaya katılan öğretmen adayı sayısı sınıf öğretmenliğinden 101 (56.1\%) ve fen bilgisi öğretmenliğinden 79 (43.9\%) olmak üzere toplamda 180 kişidir. Çalışma grubuna ait diğer demografik veriler Tablo 1'de verilmiştir.

Tablo 1. Çalışma Grubuna İlişkin Diğer Demografik Veriler

\begin{tabular}{|c|c|c|c|}
\hline \multicolumn{2}{|c|}{ Katılımcılar } & \multirow{2}{*}{$\begin{array}{l}N \\
35\end{array}$} & \multirow{2}{*}{\begin{tabular}{|c|}
$\%$ \\
19.4 \\
\end{tabular}} \\
\hline Cincivet & Erkek & & \\
\hline cinsiyet & Kadın & 145 & 80.6 \\
\hline \multirow{3}{*}{ Akademik Ortalama } & $0-1.99$ & 12 & 6.7 \\
\hline & $2.00-2.99$ & 124 & 68.9 \\
\hline & $3.00-4.00$ & 44 & 24.4 \\
\hline \multirow{5}{*}{ Mezun Olunan Lise Türü } & Genel Lise & 57 & 31.7 \\
\hline & Anadolu L. & 85 & 47.2 \\
\hline & Yab. Dil. A. Lise & 7 & 3.9 \\
\hline & Anadolu Öğretmen & 16 & 8.9 \\
\hline & $\begin{array}{l}\text { LISeSI } \\
\text { Fen Lisesi }\end{array}$ & 2 & 1.1 \\
\hline
\end{tabular}


Nur Leman BALBAĞ | Mustafa Zafer BALBAĞ

Diğer

13

7.2

\subsection{Veri Toplama Aracı}

Bu çalışmada veri toplama aracı olarak Güneş vd. (2013) tarafından geliştirilen "Yenilenebilir Enerji Kaynaklarına Yönelik Tutum Ölçeği” kullanılmıştır. Ölçek, 26 madde ve dört alt boyuttan oluşmakta olup "tamamen katılıyorum", "katılıyorum", "kararsızım", "katılmıyorum" ve "kesinlikle katılmıyorum" seçeneklerinden oluşan beşli likert tipi şeklindedir. Ölçeğin alt boyutları; Faktör 1: Uygulama İsteği (M4, M6, M10, M14, M17, M19, M21); Faktör 2: Eğitimin Önemi (M1, M8, M11, M20, M23, M24, M25); Faktör 3: Ülke Çıkarları (M2, M5, M13, M18, M22, M26); Faktör 4: Çevre Bilinci ve Yatırımlar (M3, M7, M9, M12, M15, M16) şeklindedir. Ölçeğin güvenirliği .87 ve faktörlerin güvenirliği sırasıyla .97, .80, .78 ve. 72 'dir. Bu araştırmanın analizlerine göre Cronbach alfa değeri toplamda .82 ve alt boyutlar için sırasıyla .60, .40, .78, .53 dür.

\subsection{Verilerin Analizi}

Ölçeğin güvenirlik çalışmaları yapılarak analize uygun oldukları belirlenmiştir. Analizlerin yapılacağına karar verilmeden önce normallik testi gerçekleştirilmiştir. Bu analiz sonrasında kolmogrov - smirnov değerinin ( $p>0.05$ ) uygun olması sebebiyle verilerin normal dağıldığı tespit edilmiştir. Verilerin normal dağılıma uymaları sebebiyle parametrik analizlerin yapılmasına karar verilmiştir. Yenilenebilir Enerji Kaynaklarına Yönelik Tutumların belirlenmesinde aritmetik ortalama ve standart sapma değerleri incelenmiştir. Verilerin analizinde istatistik paket programı kullanılmıştır. Araştırma verilerinin normal dağılıma uygunluğu incelenmiştir. Parametrik veya parametrik olmayan testleri kullanmak için değişkenlerin normal dağılım gösterme durumları dikkate alınmıştır. Veriler normal dağıIım gösterdiği için uygun olan parametrik testler kullanılmıştır. Sınıf ve Fen Bilgisi Öğretmen adaylarının yenilenebilir enerji kaynaklarına yönelik tutumlarının, cinsiyete ve bölüme göre farklılık gösterip göstermediğini belirlemek amacıyla ilişkisiz örneklemeler için t testi; akademik başarı ve mezun olunan lise türüne göre farklılık gösterip göstermediğini saptamak için tek yönlü varyans analizi (ANOVA) yapılmıştır.

\section{Bulgular ve Yorumlar}

Sınıf ve Fen Bilgisi Öğretmenliği öğrencilerinin yenilenebilir enerji kaynaklarına yönelik tutumlarının incelendiği bu araştırmada, öğrencilerin yenilenebilir enerjiye yönelik tutumlarının madde ortalamaları ile ilgili tanımlayıcı istatistikler Tablo 2'de verilmiştir. 
Tablo 2. Sınıf Ve Fen Bilgisi Öğretmenliği Öğrencilerinin Yenilenebilir Enerji Kaynaklarına Yönelik Tutumlarının Madde Ortalamaları İle İlgili Tanımlayıcı İstatistikler

\begin{tabular}{|c|c|c|}
\hline \multicolumn{3}{|c|}{ Maddeler - Yenilenebilir Enerji Kaynaklarına Yönelik Tutum Ölçeği } \\
\hline M1 & $\begin{array}{l}\text { Yenilenebilir enerjiyi doğru ve etkili kullanmak için eğitimin önemli bir } \\
\text { araç olduğunu düşünüyorum. }\end{array}$ & 3.7222 \\
\hline M2 & $\begin{array}{l}\text { Yenilenebilir enerji kaynağı kullanımıyla ülkelerin gelişmişlik düzeyi } \\
\text { arasında ilişki olduğunu düşünmüyorum. }\end{array}$ & 2.9944 \\
\hline M3 & $\begin{array}{l}\text { Yenilenebilir enerji kaynaklarının kullanılması, çevre açısından koruyucu } \\
\text { olmaz. }\end{array}$ & 3.2737 \\
\hline M4 & $\begin{array}{l}\text { Türkiye'nin gelecekte yenilenebilir enerji kaynaklarının kullanımıyla ilgili } \\
\text { planlarını araştırmak istemem. }\end{array}$ & 3.1333 \\
\hline M5 & $\begin{array}{l}\text { Gelişen ülkelerin enerji kaynaklarının enerji kullanımını karşılamada } \\
\text { yenilenebilir enerjinin çözüm olacağına inanmıyorum }\end{array}$ & 2.8778 \\
\hline M6 & $\begin{array}{l}\text { Yenilenebilir enerji kaynaklarıyla ilgili yapılan bilimsel toplantılara ka- } \\
\text { tılmak isterim. }\end{array}$ & 3.4389 \\
\hline M7 & $\begin{array}{l}\text { Elektronik araçların güneş pilleriyle çalışmasının çevreye çok fazla katkı- } \\
\text { sı yoktur. }\end{array}$ & 3.1000 \\
\hline M8 & $\begin{array}{l}\text { Katılacağım proje yarışması için yenilenebilir enerji kaynaklarına yönelik } \\
\text { proje hazırlamak isterim. }\end{array}$ & 3.5167 \\
\hline M9 & $\begin{array}{l}\text { Rüzgâr kullanarak elektrik enerjisi üretmenin çevreye daha yararlı } \\
\text { olacağına inanmıyorum. }\end{array}$ & 2.9778 \\
\hline M10 & $\begin{array}{l}\text { Öğretmenlik yapacağım okulda yenilenebilir enerji konusunda eğitsel } \\
\text { kampanya düzenlemek isterim. }\end{array}$ & 3.5778 \\
\hline M11 & $\begin{array}{l}\text { Öğretmenlerin enerji kaynaklarının kullanımıyla ilgili hizmet içi eğitim } \\
\text { alması gerektiğine inanıyorum. }\end{array}$ & 2.4778 \\
\hline M12 & $\begin{array}{l}\text { Türkiye de yenilenebilir enerji kaynaklarından yararlanmak için yapılan } \\
\text { yatırımlar yeterlidir. }\end{array}$ & 3.0667 \\
\hline M13 & $\begin{array}{l}\text { Katı atıkların (çöp) uygun değerlendirilmesi sonucunda atıklardan enerji } \\
\text { elde edileceğine inanmıyorum. }\end{array}$ & 3.0500 \\
\hline M14 & $\begin{array}{l}\text { Jeotermal enerji kaynaklarının kullanıldığı yerleri görmek için kaplıcala- } \\
\text { ra seyahat etmek isterim. }\end{array}$ & 3.7278 \\
\hline
\end{tabular}




\begin{tabular}{|c|c|c|}
\hline M15 & $\begin{array}{l}\text { Ülkemizin coğrafi konumunun yenilenebilir enerji kullanımı için elverişli } \\
\text { değildir. }\end{array}$ & 3.0944 \\
\hline M16 & $\begin{array}{l}\text { Rüzgâr enerjisi kullanımı için yetkili mercilere başvuruların artmasını } \\
\text { olumsuz görüyorum. }\end{array}$ & 2.9000 \\
\hline M17 & $\begin{array}{l}\text { Atıklardan yenilenebilir enerji kazanımı için geri dönüşüm uygulamala- } \\
\text { rına dikkat ederim. }\end{array}$ & 3.8002 \\
\hline M18 & $\begin{array}{l}\text { Yenilenebilir enerji kullanımının yaygınlaşması küresel ısınmanın etkisini } \\
\text { azaltacağına inanmıyorum. }\end{array}$ & 3.0056 \\
\hline M19 & $\begin{array}{l}\text { Türkiye de yürürlüğe giren yenilenebilir enerji kanunlarını takip etmek } \\
\text { istemem. }\end{array}$ & 3.2667 \\
\hline M20 & $\begin{array}{l}\text { Öğretmenlik yapacağım okul için belirli bir enerji tasarrufu planı hazır- } \\
\text { lamak isterim. }\end{array}$ & 3.5611 \\
\hline M21 & $\begin{array}{l}\text { Enerji kullanımı hakkında bilgilendirmeyi eğitim kurumlarının yapması } \\
\text { gerektiğine inanmıyorum. }\end{array}$ & 2.8667 \\
\hline M22 & $\begin{array}{l}\text { Yenilenebilir enerji kullanımının ülkelerin ekonomisine katkı sağlayaca- } \\
\text { ğını düşünmüyorum. }\end{array}$ & 3.1944 \\
\hline M23 & $\begin{array}{l}\text { Enerji kullanımı alışkanlığında, ebeveynlerin çocuklar üzerinde önemli } \\
\text { bir rol oynadığını düşünüyorum. }\end{array}$ & 3.7000 \\
\hline M24 & $\begin{array}{l}\text { Bireylere enerji tasarrufunun kazandırılmasında, öğretmenlerin etkili } \\
\text { olduğunu düşünmüyorum }\end{array}$ & 2.9333 \\
\hline M25 & $\begin{array}{l}\text { Enerji tasarrufu ve enerji kaynaklarının doğru kullanımı konusunda } \\
\text { bireyin çevresi önemlidir. }\end{array}$ & 3.5722 \\
\hline M26 & $\begin{array}{l}\text { Yenilenebilir enerji kaynaklarını enerjiye dönüştürmenin kalkınmaya } \\
\text { faydalı olacağını düşünmüyorum. }\end{array}$ & 3.0333 \\
\hline \multicolumn{2}{|c|}{ TOPLAM } & 3.2128 \\
\hline
\end{tabular}

Tablo 2'de görüldüğü gibi Sınıf ve Fen Bilgisi Öğretmeni adaylarının, yenilenebilir enerji kaynaklarına yönelik tutumlarını belirlemeyi amaçlayan ölçeğin 26 maddeden yedi madde 3'ün altında (M2, M5, M9, M11, M16, M21, M24) kalan 19 madde de üç ile dört arasında ortalamaya sahiptir. Bu maddelerden en yüksek ortalamaya sahip 17. ve 14 . maddeler iken, en düşük ortalamaya sahip maddeler 11. ve 21. maddelerdir.

Sınıf ve Fen Bilgisi Öğretmen Adaylarının, yenilenebilir enerji kaynaklarına yönelik tutum ortalamalarının ölçeğin tümü ve alt boyutlara göre incelenmesi Tablo 3'de verilmiştir. 
Tablo 3. Sınıf Ve Fen Bilgisi Öğretmen Adaylarının, Yenilenebilir Enerji Kaynaklarına Yönelik Tutum Ortalamalarının Ölçeğin Tümü ve Alt Boyutlara Göre İncelenmesi

\begin{tabular}{cccccc}
\hline $\begin{array}{c}\text { Alt Boyutlar ve Toplam } \\
\text { Ortalamaları }\end{array}$ & $N$ & Minimum & Maksimum & $\bar{X}$ & Std.Sapma \\
\hline $\begin{array}{c}\text { Faktör 1. Uygulama } \\
\text { İsteği }\end{array}$ & 180 & 1.14 & 4.86 & 3.4016 & .64735 \\
$\begin{array}{c}\text { Faktör 2. Eğitimin } \\
\text { Önemi }\end{array}$ & 180 & 1.57 & 4.57 & 3.3548 & .57471 \\
$\begin{array}{c}\text { Faktör 3. Ülke Çıkarları } \\
\begin{array}{c}\text { Faktör 4: Çevre Bilinci } \\
\text { ve Yatırımlar }\end{array}\end{array}$ & 180 & 1.17 & 5.00 & 3.0259 & .92651 \\
$\quad$ Toplam & 180 & 1.33 & 4.67 & 3.0688 & .72078 \\
\hline
\end{tabular}

Tablo 3'de Sınıf ve Fen Bilgisi Öğretmen Adaylarının, yenilenebilir enerji kaynaklarına yönelik tutumlarının ölçeğin tümü ve alt boyutlarındaki ortalamaları görülmektedir. Buna göre toplamda ve alt boyutlar açısından incelendiğinde ortalamaların hepsinin 3'ün üzerinde olduğu görülmektedir. Bu sonuçlara göre hem madde ortalamaları hem de alt boyut ve toplam puanlar incelendiğinde, öğretmen adaylarının söz konusu yenilenebilir enerji kaynaklarına ilişkin tutumlarının, genel olarak olumlu ve yüksek olduğu söylenebilir.

Sınıf ve Fen Bilgisi Öğretmen adaylarının, yenilenebilir enerji kaynaklarına yönelik tutumlarının cinsiyete göre t-testi Sonuçları Tablo 4'de verilmiştir.

Tablo 4. Sınıf ve Fen Bilgisi Öğretmen adaylarının, yenilenebilir enerji kaynaklarına yönelik tutumlarının Cinsiyete Göre t-testi Sonuçları

\begin{tabular}{cccccccc}
\hline \hline & Cinsiyet & $N$ & $\bar{X}$ & $\begin{array}{c}\text { Std. } \\
\text { Sapma }\end{array}$ & Std. Hata Ort. & $t$ & $p$ \\
\hline $\begin{array}{c}\text { Faktör 1. } \\
\text { Uygulama İsteği }\end{array}$ & Kadın & 145 & 3.4700 & .62518 & .05192 & \\
\cline { 2 - 7 } & Erkek & 35 & 3.1184 & .66960 & .11318 & & \\
\hline $\begin{array}{c}\text { Faktör 2. } \\
\text { Eğitimin Önemi }\end{array}$ & Kadın & 145 & 3.3921 & .55578 & .04616 & \\
\cline { 2 - 7 } & Erkek & 35 & 3.2000 & .63246 & .10690 & & \\
\hline Faktör 3. & Kadın & 145 & 3.0644 & .91079 & .07564 & 1.134 & .076 \\
\hline
\end{tabular}


Nur Leman BALBAĞ | Mustafa Zafer BALBAĞ

\begin{tabular}{cccccccc}
\hline \hline Ülke Çıkarları & Erkek & 35 & 2.8667 & .98668 & .16678 & & \\
\hline $\begin{array}{c}\text { Faktör 4: } \\
\text { Çevre Bilinci ve } \\
\text { Yatırımlar }\end{array}$ & Kadın & 145 & 3.1084 & .69154 & .05743 & & \\
\cline { 2 - 6 } & Erkek & 35 & 2.9048 & .82177 & .13890 & & \\
\hline \multirow{2}{*}{ Toplam } & Kadın & 145 & 3.2587 & .53536 & .04446 & & \\
\cline { 2 - 6 } & Erkek & 35 & 3.0224 & .61852 & .10455 & & \\
\hline
\end{tabular}

Tablo 4'de Sınıf ve Fen Bilgisi Öğretmen adaylarının yenilenebilir enerji kaynaklarına yönelik tutumlarının cinsiyete göre farklılaşmasını test etmek amacıyla bağımsız örneklemler grubu t testi analiz sonuçları görülmektedir. Test sonuçlarına göre faktör 1 alt boyutunda $(\mathrm{t}: 2,945, \mathrm{p}<.01)$ ve toplam puanlarda $(\mathrm{t}: 2,272, \mathrm{p}<.05)$ kadın öğretmen adaylarına ait ortalamaların (Faktör 1: 3,47, Toplam: 3,26), erkek öğretmen adaylarına ait ortalamalara (Faktör 1: 3,12, Toplam puan: 3,02) göre istatistiksel olarak anlamlı şekilde daha yüksek olduğu görülmüştür. Diğer alt boyutlarda cinsiyete göre anlamlı bir farklılaşma tespit edilememiştir.

Sınıf ve Fen Bilgisi Öğretmen adaylarının, yenilenebilir enerji kaynaklarına yönelik tutumlarının bölüme göre t-testi Sonuçları Tablo 5'de verilmiştir.

Tablo 5. Sınıf ve Fen Bilgisi Öğretmen adaylarının, yenilenebilir enerji kaynaklarına yönelik tutumlarının Bölüme Göre t-testi Sonuçları

\begin{tabular}{|c|c|c|c|c|c|c|c|}
\hline & Bölüm & $N$ & $\bar{X}$ & Std. Sapma & Std. Hata Ort. & $t$ & $p$ \\
\hline Faktör 1. & F.B.Ö. & 79 & 3.4377 & 67951 & .07645 & \multirow[b]{2}{*}{0.660} & \multirow[b]{2}{*}{.510} \\
\hline $\begin{array}{c}\text { Uygulama } \\
\text { İsteği }\end{array}$ & S.Ö. & 101 & 3.3734 & .62302 & .06199 & & \\
\hline Faktör 2. & F.B.Ö. & 79 & 3.3201 & .57835 & .06507 & \multirow[b]{2}{*}{-0.715} & \multirow[b]{2}{*}{.475} \\
\hline $\begin{array}{l}\text { Eğitimin } \\
\text { Önemi }\end{array}$ & S.Ö. & 101 & 3.3819 & .57325 & .05704 & & \\
\hline Faktör 3. & F.B.Ö. & 79 & 3.0823 & .93708 & .10543 & \multirow[b]{2}{*}{0.721} & \multirow[b]{2}{*}{.472} \\
\hline $\begin{array}{c}\text { Ülke } \\
\text { Çıkarları }\end{array}$ & S.Ö. & 101 & 2.9818 & .92041 & .09158 & & \\
\hline
\end{tabular}




\begin{tabular}{|c|c|c|c|c|c|c|c|}
\hline Faktör 4: & F.B.Ö. & 79 & 3.1272 & .73148 & .08230 & \multirow{3}{*}{0.961} & \multirow{3}{*}{.338} \\
\hline Çevre & \multirow{3}{*}{ s.ö. } & \multirow{3}{*}{101} & \multirow{3}{*}{3.0231} & \multirow{3}{*}{.71260} & \multirow{3}{*}{.07091} & & \\
\hline Bilinci ve & & & & & & & \\
\hline Yatırımlar & & & & & & & \\
\hline \multirow{2}{*}{ Toplam } & F.B.Ö. & 79 & 3.2418 & .57155 & .06430 & \multirow{2}{*}{0.616} & \multirow{2}{*}{.539} \\
\hline & s.ö. & 101 & 3.1901 & .55004 & .05473 & & \\
\hline
\end{tabular}

Tablo 5'de Sınıf ve Fen Bilgisi Öğretmen adaylarının yenilenebilir enerji kaynaklarına yönelik tutumlarının bölüme göre farklılaşmasını test etmek amacıyla bağımsız örneklemler grubu t testi analiz sonuçları görülmektedir. Öğretmen adaylarının ortalamaları incelendiğinde, toplamda ve alt boyutlarda farklılaşma istatistiksel olarak anlamlı değildir $(p<.05)$. Sonuç olarak SÖ ve FBÖ adayları arasında yenilenebilir enerji kaynaklarına yönelik tutumları arasında fark yoktur.

Sınıf ve Fen Bilgisi Öğretmen adaylarının, yenilenebilir enerji kaynaklarına yönelik tutumlarının Akademik Ortalamaya Göre ANOVA Sonuçları Tablo 6'da verilmiştir.

Tablo 6. Sınıf ve Fen Bilgisi Öğretmen adaylarının, yenilenebilir enerji kaynaklarına yönelik tutumlarının Akademik Ortalamaya Göre ANOVA Sonuçları

\begin{tabular}{|c|c|c|c|c|c|c|c|}
\hline Akader & nik Başarı & $\begin{array}{l}\text { Kareler Top- } \\
\text { lamı }\end{array}$ & $s d$ & Kareler Ort. & $F$ & $p$ & Fark \\
\hline \multirow{3}{*}{$\begin{array}{c}\text { Faktör 1. Uygu- } \\
\text { lama İsteği }\end{array}$} & Gruplar Arası & 1.331 & 2 & .666 & 1.599 & .205 & \multirow{3}{*}{ - } \\
\hline & Grup İçi & 73.682 & 177 & .416 & & & \\
\hline & Toplam & 75.013 & 179 & & & & \\
\hline \multirow{3}{*}{$\begin{array}{c}\text { Faktör 2. Eğiti- } \\
\text { min Önemi }\end{array}$} & Gruplar Arası & 1.043 & 2 & .522 & 1.589 & .207 & \multirow{3}{*}{ 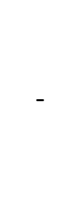 } \\
\hline & Grup İçi & 58.078 & 177 & .328 & & & \\
\hline & Toplam & 59.121 & 179 & & & & \\
\hline
\end{tabular}


Nur Leman BALBAĞ | Mustafa Zafer BALBAĞ

\begin{tabular}{|c|c|c|c|c|c|c|c|}
\hline \multirow{3}{*}{$\begin{array}{c}\text { Faktör } 3 . \text { Ülke } \\
\text { Çıkarları }\end{array}$} & Gruplar Arası & .055 & 2 & .027 & .032 & .969 & \multirow{3}{*}{-} \\
\hline & Grup İçi & 153.601 & 177 & .868 & & & \\
\hline & Toplam & 153.656 & 179 & & & & \\
\hline \multirow{3}{*}{$\begin{array}{c}\text { Faktör 4: Çevre } \\
\text { Bilinci ve Yatırım- } \\
\text { lar }\end{array}$} & Gruplar Arası & .070 & 2 & .035 & .067 & .935 & \multirow{3}{*}{-} \\
\hline & Grup İçi & 92.924 & 177 & .525 & & & \\
\hline & Toplam & 92.994 & 179 & & & & \\
\hline \multirow{3}{*}{ Toplam } & Gruplar Arası & .258 & 2 & .129 & .411 & .663 & \multirow{3}{*}{-} \\
\hline & Grup İçi & 55.594 & 177 & .314 & & & \\
\hline & Toplam & 55.853 & 179 & & & & \\
\hline
\end{tabular}

Tablo 6'de Sınıf ve Fen Bilgisi Öğretmen Adaylarının yenilenebilir enerji kaynaklarına yönelik tutumlarının akademik başarılarına göre farklılaşmasını test etmek amacıyla tek yönlü varyans analizi (ANOVA) sonuçları görülmektedir. Öğretmen adaylarının ortalamaları incelendiğinde, toplamda ve alt boyutlarda farklılaşma istatistiksel olarak anlamlı değildir $(p<.05)$.

Sınıf ve Fen Bilgisi Öğretmen adaylarının, yenilenebilir enerji kaynaklarına yönelik tutumlarının mezun olunan lise türüne göre ANOVA Sonuçları Tablo 7'de verilmiştir.

Tablo 7. Sınıf ve Fen Bilgisi Öğretmen adaylarının, yenilenebilir enerji kaynaklarına yönelik tutumlarının Mezun Olunan Lise Türüne Göre ANOVA Sonuçları

\begin{tabular}{|c|c|c|c|c|c|c|c|}
\hline \multicolumn{2}{|c|}{ Mezun Olunan Lise Türü } & \multirow{2}{*}{$\begin{array}{c}\text { Kareler } \\
\text { Toplamı } \\
1.067\end{array}$} & \multirow{2}{*}{$\begin{array}{l}\text { sd } \\
5 \\
\end{array}$} & \multirow{2}{*}{$\begin{array}{c}\text { Kareler Ort. } \\
.213\end{array}$} & \multirow{2}{*}{$\begin{array}{c}F \\
.502 \\
\end{array}$} & \multirow{2}{*}{$\begin{array}{c}p \\
.774 \\
\end{array}$} & \multirow{3}{*}{$\begin{array}{c}\text { Fark } \\
\\
\text { - }\end{array}$} \\
\hline \multirow{3}{*}{$\begin{array}{l}\text { Faktör } 1 . \text { Uygu- } \\
\text { lama İsteği }\end{array}$} & Gruplar Arası & & & & & & \\
\hline & Grup İçi & 73.946 & 174 & .425 & & & \\
\hline & Toplam & 75.013 & 179 & & & & \\
\hline \multirow{3}{*}{$\begin{array}{c}\text { Faktör 2. Eğiti- } \\
\text { min Önemi }\end{array}$} & Gruplar Arası & 4.449 & 5 & .890 & 2.832 & .017 & $2>1$ \\
\hline & Grup İçi & 54.673 & 174 & .314 & & & $4>1$ \\
\hline & Toplam & 59.121 & 179 & & & & $5>1$ \\
\hline
\end{tabular}


Eskişehir Osmangazi Üniversitesi Sosyal Bilimler Dergisi

\begin{tabular}{|c|c|c|c|c|c|c|c|}
\hline \multirow{3}{*}{$\begin{array}{c}\text { Faktör 3. Ülke } \\
\text { Çıkarları }\end{array}$} & Gruplar Arası & 2.615 & 5 & .523 & .602 & .698 & \multirow{3}{*}{ - } \\
\hline & Grup İçi & 151.041 & 174 & .868 & & & \\
\hline & Toplam & 153.656 & 179 & & & & \\
\hline \multirow{3}{*}{$\begin{array}{c}\text { Faktör 4: Çevre } \\
\text { Bilinci ve Yatı- } \\
\text { rımlar }\end{array}$} & Gruplar Arası & 4.196 & 5 & .839 & 1.644 & .151 & \multirow{3}{*}{-} \\
\hline & Grup İçi & 88.798 & 174 & .510 & & & \\
\hline & Toplam & 92.994 & 179 & & & & \\
\hline \multirow{3}{*}{ Toplam } & Gruplar Arası & 1.704 & 5 & .341 & 1.095 & .365 & \multirow{3}{*}{-} \\
\hline & Grup İçi & 54.149 & 174 & .311 & & & \\
\hline & Toplam & 55.853 & 179 & & & & \\
\hline
\end{tabular}

1: Genel Lise, 2:Anadolu Lisesi, 3: Yabancı dil ağırlıklı lise, 4: Anadolu Öğretmen Lisesi, 5: Fen Lisesi, 6: Diğer

Tablo 7'da görüldüğü üzere, Sınıf ve Fen Bilgisi Öğretmen Adaylarının yenilenebilir enerji kaynaklarına yönelik tutumlarının mezun oldukları lise türüne göre farklılaşmasını test etmek amacıyla tek yönlü varyans analizi (ANOVA) yapılmıştır. Öğretmen adaylarının mezun olunan lise türüne göre ortalamaları, Faktör 1, Faktör 3, Faktör 4 alt boyutlarında ve toplamda istatistiksel olarak anlamlı değildir ( $p<.05)$. Anlamlı fark Faktör 2: Eğitimin önemi alt boyutunda görülmektedir. Anadolu Lisesi, Anadolu Öğretmen Lisesi ve Fen Lisesinden mezun olan öğretmen adaylarının ortalamaları, Genel liselerden mezun olan öğrencilerin ortalamalarından istatistiksel olarak anlamlı bir şekilde yüksektir.

Sınıf ve Fen Bilgisi Öğretmen adaylarının, yenilenebilir enerji kaynaklarına yönelik tutumlarının mezun olunan lise türlerinin Faktör 2'ye Göre Ortalama Sonuçları Tablo 8'de verilmiştir.

Tablo 8. Sınıf ve Fen Bilgisi Öğretmen adaylarının, yenilenebilir enerji kaynaklarına yönelik tutumlarının Mezun Olunan Lise Türlerinin Faktör 2’ye Göre Ortalama Sonuçları

\begin{tabular}{cccccc}
\hline \hline & Faktör 2 & $N$ & $\bar{X}$ & Std. Sapma & Std. Hata \\
\hline & 1.00 & 57 & 3.1604 & .59153 & .07835 \\
\cline { 2 - 6 } & 2.00 & 85 & 3.4303 & .53293 & .05780 \\
\cline { 2 - 6 } $\begin{array}{c}\text { Faktör 2. } \\
\text { Eğitimin } \\
\text { Önemi }\end{array}$ & 3.00 & 7 & 3.3673 & .53995 & .20408 \\
\cline { 2 - 6 } & 4.00 & 16 & 3.5982 & .54265 & .13566 \\
\cline { 2 - 6 } & 5.00 & 2 & 4.0000 & .60609 & .42857 \\
\hline
\end{tabular}




\begin{tabular}{ccccc}
\hline \hline 6.00 & 13 & 3.3077 & .62501 & .17335 \\
\hline Total & 180 & 3.3548 & .57471 & .04284 \\
\hline
\end{tabular}

1: Genel Lise, 2:Anadolu Lisesi, 3: Yabancı dil ağırlıklı lise, 4: Anadolu Öğretmen Lisesi, 5: Fen Lisesi, 6: Diğer

Tablo 8'de görüldüğü üzere, Faktör 2: Eğitimin önemi alt boyutunda, Anadolu Lisesi, Yabancı dil ağırlıklı lise, Anadolu Öğretmen Lisesi, Fen Lisesi ve Diğer liselerden mezun olan öğretmen adaylarının ortalamaları, Genel liselerden mezun olan öğretmen adaylarının ortalamalarından istatistiksel olarak anlamlı bir şekilde yüksektir.

\section{Sonuç ve Tartışma}

Sınıf ve Fen Bilgisi Öğretmeni adaylarının, yenilenebilir enerji kaynaklarına yönelik tutumlarını belirlemeyi amaçlayan ölçeğin 26 maddeden yedi madde 3'ün altında, kalan 19 madde de üç ile dört arasında ortalamaya sahiptir. Öğretmen adaylarının söz konusu yenilenebilir enerji kaynaklarına ilişkin tutumlarının, genel olarak olumlu olduğu söylenebilir. Cebesoy \& Karışan (2017); Bilen vd. (2013); Fırat vd. (2012); Tiftikçi, (2014); Yenice, \& Tunç (2018); Karatepe vd. (2012); Bozdoğan \& Yiğit (2014); Çelikler \& Kara (2011)'in yaptığı çalışmalar bu çalışmanın sonuçları ile uyumludur.

Sınıf ve Fen Bilgisi Öğretmen adaylarının yenilenebilir enerji kaynaklarına yönelik tutumlarının cinsiyete göre analizinde, faktör 1: Uygulama isteği alt boyutunda ve toplam puanlarda kadın öğretmen adaylarına ait ortalamaların, erkek öğretmen adaylarına ait ortalamalara göre istatistiksel olarak anlamlı şekilde daha yüksek olduğu görülmüştür. Karatepe vd. (2012) ile Bilen vd. (2013) tarafından yapılan çalışmaların sonucu bu çalışmanın sonuçlarına benzerlik göstermektedir. Diğer alt boyutlarda cinsiyete göre anlamlı bir farklılaşma tespit edilememiştir. Bozdoğan \& Yiğit (2014) tarafından yapılan çalışmanın sonucu ise bu durumu desteklemektedir.

Sınıf ve Fen Bilgisi Öğretmen adaylarının yenilenebilir enerji kaynaklarına yönelik tutumlarının bölüme göre analizi incelendiğinde, toplamda ve alt boyutlarda farklılaşma istatistiksel olarak anlamlı değildir. Hem sınıf hem de fen bilgisi öğretmen adaylarının yenilenebilir enerji kaynaklarına yönelik tutumları arasında fark yoktur. Bozdoğan \& Yiğit (2014) tarafından yapılan çalışmanın sonucu bu sonucu destekler niteliktedir. Bozdoğan \& Yiğit (2014)'in yaptığı çalışmada Fen Bilimleri ve Sınıf öğretmen adaylarının yarısından fazlasının "çevreye ve insan sağlığına zarar vermeyen doğa dostu enerji türü olduğu için" güneş, rüzgâr, su ve jeotermal enerji türlerini desteklediklerini söylemektedir. Bu sonuca göre, sınıf ve fen bilgisi öğretmen adaylarının ikisi de yenilenebilir enerji konusunda olumlu ve destekleyici görüşlere sahiptir. Bu nedenle yapılan çalışmada anlamlı farkın oluşmaması sınıf ve fen bilgisi öğretmenlerinin aynı düşüncede olmalarından dolayı olabilir. 
Sınıf ve Fen Bilgisi Öğretmen Adaylarının yenilenebilir enerji kaynaklarına yönelik tutumlarının akademik başarılarına göre analizi incelendiğinde, toplamda ve alt boyutlarda farklılaşma istatistiksel olarak anlamlı değildir. Tiftikçi, (2014) tarafından yapılan çalışmanın sonucu, bu çalışmanın sonucuna benzerlik göstermektedir.

Sınıf ve Fen Bilgisi Öğretmen Adaylarının yenilenebilir enerji kaynaklarına yönelik tutumlarının mezun oldukları lise türüne göre analizi incelendiğinde, Faktör 1:Uygulama isteği, Faktör 3:Ülke çıkarları, Faktör 4: Çevre bilinci ve yatırımlar alt boyutlarında ve toplamda istatistiksel olarak anlamlı bir fark yoktur. Faktör 1, Faktör 3, Faktör 4 alt boyutlarında ve toplamda anlamlı farkın çıkmayışı, Tiftikçi, (2014) ve Fırat vd. (2012) tarafından yapılan çalışmaların sonuçları ile benzerlik göstermektedir. Ancak bu çalışmada, Faktör 2: Eğitimin önemi alt boyutunda anlamlı bir fark görülmektedir. Faktör 2'de, Anadolu Lisesi, Anadolu Öğretmen Lisesi ve Fen Lisesinden mezun olan öğretmen adaylarının ortalamaları, Genel liselerden mezun olan öğrencilerin ortalamalarından istatistiksel olarak anlamlı bir şekilde yüksektir.

\section{5. Öneriler}

Sınıf ve Fen Bilgisi Öğretmeni adaylarının, yenilenebilir enerji kaynaklarına yönelik tutumlarını belirlenmesinin amaçlandığı bu çalışmanın sonuçları doğrultusunda araştırmacılara yönelik şu önerilerde bulunulmuştur

1. Öğretmen adaylarının yenilenebilir enerji kaynaklarına ilişkin farkındalık ve tutumlarının tespit edilmesi ve artırılmasına yönelik nitel araştırmalar gerçekleştirilebilir.

2. Bu araştırma farklı bölümlerde ve farklı değişkenler işe koşularak da gerçekleştirilebilir.

\section{Kaynaklar}

Bilen, K., Özel, M. \& Sürücü, A. (2013). Fen Bilgisi Öğretmen Adaylarının Yenilenebilir Enerjiye Yönelik Tutumları. Dumlupınar Üniversitesi Sosyal Bilimler Dergisi, 36, 101111.

Bindak, R., (2004). Geometri Tutum Ölçeği Güvenirlik Geçerlik Çalışması ve Bir Uygulama, Dicle Üniv. Fen Bilimleri Enstitüsü, Doktora Tezi.

Bozdoğan A. E., \& Yiğit, D. (2014). Öğretmen Adaylarının Alternatif Enerji Kaynaklarına Yönelik Görüşlerinin Farklı Değişkenler Açısından İncelenmesi, Elektronik Eğitim Bilimleri Dergisi, 3 (6): 113-130.

Cebesoy, Ü. B. (2016). Çevre Sorunları ve Çözümler. H. Genç. (Ed.). (ss.53-72). Çevre Eğitimi, İstanbul: Lisans Yayıncılık. 
Cebesoy, Ü. B., \& Karışan, D. (2017). “Fen Bilgisi Öğretmen Adaylarının Yenilenebilir Enerji Kaynaklarına Yönelik Bilgilerinin, Tutumlarının ve Bu Kaynakların Öğretimi Konusundaki Öz-yeterlik Algılarının İncelenmesi”, YYÜ Eğitim Fakültesi Dergisi (YYU Journal Of EducationFaculty), 14 (1): 1377-1415.

Çelikler, D. \& Kara, F. (2011). İlköğretim matematik ve sosyal bilgiler öğretmen adaylarının yenilenebilir enerji konusundaki farkındalıkları.

Fırat, A., Sepetçioğlu, H. \& Kiraz, A. (2012). Öğretmen Adaylarının Yenilenebilir Enerjiye ìlişkin Tutumlarının İncelenmesi. Hacettepe Üniversitesi Eğitim Fakültesi Dergisi, 1, 216-224.

Güneş, T., Alat, K., \& Gözüm, A.I.C. (2013). “Fen Öğretmeni Adaylarına Yönelik Yenilenebilir Enerji Kaynakları Tutum Ölçeği: Geçerlilik ve Güvenirlik Çalışması”, Eğitim Bilimleri Araştırmaları Dergisi, 3 (2): 269-289.

Karasar, N. (2009). Bilimsel Araştırma Yöntemi, 20. Baskı, Nobel Yayın Dağıtım, Ankara.

Karatepe,Y.,Varbak, N., Keçebas, A. \& Yumurtacı, M. (2012). The Levels of Awareness About The Renewable Energy Sources Of University Students in Turkey. Renewable Energy.

Koroneos, C., Spachos, T., \& Moussiopoulos, N. (2003). Enerrgy analysis of renewable energy sources. Renewable energy, 28(2), 295-310.

Liarakou, G., Gavrilakis, C., \& Flouri, E. ( 2009). Secondary School Teachers' Knowledge and Attitudes Towards Renewable Energy Sources, Journal Science Education Technology, 18, 20-129.

Saatçioğlu, C., \& Küçükaksoy, i. (2004). Türkiye Ekonomisinin Enerji Yoğunluğu Ve Önemli Enerji Taşıma Projelerinin Ekonomiye Etkisi. Dumlupınar Üniversitesi Sosyal Bilimler Dergisi, 11, 19-39

Tiftikçi, H. í. (2014). Farklı Bölümlerde Öğrenim Görmekte Olan Son Sınıf Üniversite Öğrencilerinin Yenilenebilir Enerji Kaynakları Hakkındaki Farkındalıkları. Gazi Üniversitesi Eğitim Bilimleri Enstitüsü Yüksek Lisans Tezi. Ankara.

Yenice, N. \& Tunç, G.A. (2018). “Fen Bilgisi Öğretmen Adaylarının Çevre Sorunlarına Yönelik Farkındalıkları İle Yenilenebilir Enerji Kaynaklarına Yönelik Tutumlarının İncelenmesi", Uludağ Üniversitesi, Eğitim Fakültesi Dergisi 31 (1): 207-222. 